\title{
Bioluminescence Imaging of Matrix Metalloproteinases-2 and -9 Activities in Ethanol-injured Cornea of Mice
}

\author{
SEUNG-BO PARK ${ }^{1 \#}$, SEUNG HYO JUNG ${ }^{1 \#}$, HENGZHE JIN ${ }^{1}$, SU JUNG KIM ${ }^{1}$, YUNKYOUNG RYU ${ }^{1}$, \\ KYUNG-JIN LEE ${ }^{1}$, BOKYUNG KIM ${ }^{1}$, HYUN JIN SHIN ${ }^{2}$ and KYUNG-JONG WON ${ }^{1}$ \\ ${ }^{1}$ Department of Physiology, Konkuk University School of Medicine, Seoul, Republic of Korea; \\ ${ }^{2}$ Department of Ophthalmology, Konkuk Medical Center, \\ Konkuk University School of Medicine, Seoul, Republic of Korea
}

\begin{abstract}
Background/Aim: This study aimed to investigate the usefulness of in vivo bioluminescence imaging (BLI) to examine the role of matrix metalloproteinases (MMP)-2 and MMP-9 activation in the development and healing of ethanol-induced damage in the cornea of mice. Materials and Methods: Mouse corneal injury was induced by topical treatment with $20 \%$ ethanol. BLI was obtained from the ocular region of mice intravenously injected with an active$M M P-2 / 9$ probe. In vivo results were validated in primary corneal epithelial cells. Results: BLI indicated that treatment of the eye with $20 \%$ ethanol elevated MMP-2/9 activity, which was inhibited by the application of eye drops (hyaluronic acid and serum). Treatment of corneal epithelial cells with $20 \%$ ethanol increased the activities of MMP-2 and MMP-9, which were also inhibited by eye drops. Conclusion: BLI can be applied in vivo in mice with corneal injury to examine the activity of MMPs and clarify the efficacy of eye drops.
\end{abstract}

Injuries caused by chemicals including alkali and ethanol cause serious clinical ophthalmological problems, such as

This article is freely accessible online.

\#These Authors contributed equally to this work.

Correspondence to: Kyung-Jong Won, DVM, Ph.D., Department of Physiology, Konkuk University School of Medicine, 120 Neungdong-ro, Gwangjin-gu, Seoul 05029, Republic of Korea. Tel: +82 220307846, e-mail: kjwon@kku.ac.kr; Hyun Jin Shin, MD, $\mathrm{PhD}$, Departments of Ophthalmology, Konkuk Medical Center, Konkuk University School of Medicine, 120 Neungdong-ro, Gwangjin-gu, Seoul 05029, Republic of Korea. Tel: +82 220867656,e-mail: shineye@kuh.ac.kr

Key Words: Corneal injury, matrix metalloproteinases, bioluminescence imaging. limbal stem cell damage, corneal melt and corneal scarring (1). Ethanol is being used in ocular surface surgeries such as laser-assisted subepithelial keratectomy and pterygium excision to remove the epithelium during procedures of surface ablation (2). It is well known that topical treatment of the eye surface with ethanol can induce morphological and functional changes and damage the cornea (3). These lesions of the corneal by application of ethanol are due to a variety of mechanisms including cell death and apoptosis or severe inflammatory reactions of corneal epithelial cells (4).

Matrix metalloproteinases (MMPs) are zinc-dependent peptidases that play a fundamental role in inflammation and apoptotic processes when the extracellular matrix (ECM) is excessively damaged (5). MMPs are expressed in the cornea of animals and human (6). Multi-isoforms of MMPs are upregulated in corneal epithelial cells during injury and healing $(5,7)$. MMP-2 and MMP-9 (gelatinases $\mathrm{A}$ and $\mathrm{B}$, respectively) are also involved in the process of degradation of corneal epithelium in response to a variety of agents (8). The levels of MMP-9 transcripts produced by human corneal limbal epithelial cells is elevated in ethanol-induced injury $(9,10)$. In addition, $70 \%$ ethanol can induce corneal epithelium damages and up-regulate the expression of MMP2 and MMP-9 (11). Eye drops containing hyaluronic acid (HA) can protect the ocular surface epithelium by facilitating corneal epithelial healing and by regulating the expression of MMP-2 and MMP-9 (12). Moreover, platelet-activation factor, a bioactive lipid, can elevate the expression of MMPs. Its antagonist can protect against the development of epithelial damages by reducing the capacity of MMPs to degrade gelatin (13). Elevated activities of MMP-2 and MMP-9 are associated with every step of ocular surface injury and can lead to delayed corneal wound healing (14).

Bioluminescence imaging (BLI) is an optical imaging technique that visualizes biological processes using luciferase-catalyzed reactions with a target substrate (15). It has been documented that BLI data can be used for non- 
invasive visualization of a variety of biological processes, including retinoblastoma growth and metastasis in vivo (1517). BLI can be used to obtain a repeated and longitudinal image to analyze localization and quantify drug efficacy in experiment animals $(17,18)$. Therefore, BLI has been used in the diagnosis and initial management of eye injury (19, 20). Previously, a representative BLI study has shown that an annexin $\mathrm{V}$ probe can be used on ethanol-treated corneal epithelium to detect apoptosis (21). Moreover, a longitudinal analysis using BLI has been performed to study tumorigenesis in mice and determine the expression of MMP2 (22). As mentioned above, MMP-2 and MMP-9 expression levels are correlated with corneal functions including the growth of corneal epithelial cells (14). However, no study has examined corneal epithelial MMP-2 and MMP-9 activities in vivo during ethanol-induced injury or application of protective eye drops. Therefore, the objective of this study was to investigate the usefulness of BLI for examining MMP$2 / 9$ activity in corneal pathophysiology in vivo. BLI changes in cornea were assessed using an MMP-2/9 probe after ethanol-induced injury and treatment with protective eye drops. The results obtained from BLI analysis were validated by analyzing the activities of MMP-2 and MMP-9 in primary corneal epithelial cells.

\section{Materials and Methods}

Materials. Dulbecco's modified eagle medium (DMEM), fetal bovine serum (FBS), and phosphate-buffered saline (PBS) were purchased from Hyclone (Logan, UT, USA). Sodium hyaluronate (HA) was obtained from Taejoon Pharmaceuticals (Seoul, Republic of Korea). Penicillin/streptomycin and trypsin-ethylene diamine tetraacetic acid (EDTA) were purchased from Fisher Scientific (Pittsburgh, PA, USA). NpFlamma ${ }^{\circledR}$ MMP-2/9 probe was purchased from BioActs (Incheon, Republic of Korea). Antibodies used in this study included anti-MMP-2, anti- $\beta$-actin (Santa Cruz Biotechnology, Santa Cruz, CA, USA), anti-MMP-9 (Abcam Plc, Cambridge, UK), and antiactive MMP-9 (Merck KGaA, Darmstadt, Germany).

Animals and BLI measurement. All animal experiments were performed in accordance with the Guide for the Care and Use of Laboratory Animals published by the US National Institutes of Health (NIH publication No. 85-23, revised 1996). They were approved by Animal Subjects Committee of Konkuk University, Korea (Approval number: KU19118). ICR (Institute of Cancer Research) mice (8-week-old, male; Nara Biotech, Seoul, Republic of Korea) were given free access to water and food pellets.

Before BLI and application of alcohol to eyes, mice were anesthetized by intraperitoneal injection of Zoletil ${ }^{\circledR}(40 \mathrm{mg} / \mathrm{kg}$ body weight; Virbac Laboratories, Carros, France) and Rompun ${ }^{\circledR}(10 \mathrm{mg} / \mathrm{kg}$ body weight; Bayer Korea, Seoul, Republic of Korea). Adequacy of anesthesia was determined based on the lack of reflex response to foot pinching. A 6-mm-diameter filter paper disk (Advantec, Tokyo, Japan) soaked in $20 \%$ ethanol was placed on the right eye surface of the anesthetized mouse for $30 \mathrm{~s}$ to induce corneal injury. The ethanoltreated eyes were washed with $20 \mu \mathrm{l}$ of normal saline immediately after removing the paper disk, and then wiped the saline water with sterile cotton balls. NpFlamma ${ }^{\circledR}$ MMP-2/9 probe solution $(1.2 \mu \mathrm{g} / \mu \mathrm{l})$ was prepared by diluting it with PBS. It was then injected intravenously at $100 \mu \mathrm{l} /$ mouse via the tail vein. BLI intensity was measured and detected at various time points (i.e., $3 \mathrm{~h}, 6 \mathrm{~h}, 12 \mathrm{~h}, 24 \mathrm{~h}$, and $48 \mathrm{~h}$ after injection of the probe). BLI was performed using an Ami HTX (Spectral Instruments Imaging, Tucson, AZ, USA) at excitation wavelength of $683 \mathrm{~nm}$ and emission wavelength of $694 \mathrm{~nm}$. Non-injury and non-treated control images were obtained for the left eye of mice administered $100 \mu \mathrm{l} /$ mouse saline. High concentration serum and HA were diluted in PBS to obtain $50 \%$ and $0.15 \%$ solutions, respectively, for topical treatment. Mice received $10 \mu \mathrm{l} /$ mouse of eye drop. Regions of interest (ROI) were selected from the ocular region of the image. Photon intensity of BLI was quantified automatically using a dedicated software (Spectral Instruments Imaging) as photon counts per second $(\mathrm{p} / \mathrm{s})$ in background-subtracted ROI.

Cell culture and viability assay. Primary corneal epithelial cells were purchased from the American Type Culture Collection (ATCC, Manassas, VA, USA). These cells were cultured in DMEM/F-12 supplemented with $10 \% \mathrm{FBS}, 1 \%$ penicillin/streptomycin, and epidermal growth factor $(10 \mathrm{ng} / \mathrm{ml})$ and incubated at $37^{\circ} \mathrm{C}$ in a humidified incubator with $95 \%$ air and $5 \% \mathrm{CO}_{2}$.

Cell viability was analyzed using 2,3-bis(2-metrhoxy-4nitro-5sulfophenyl)-2H-tetrazolium-5-carboxamilide inner salt (XTT) assay with a WelCount ${ }^{\mathrm{TM}}$ cell proliferation assay kit (Welgene, Daegu, Republic of Korea). Briefly, corneal epithelial cells $\left(1 \times 10^{4}\right.$ cells/well) were seeded into a 96-well plate and incubated at $37^{\circ} \mathrm{C}$ for $48 \mathrm{~h}$. After adding XTT $(200 \mu \mathrm{g} / \mathrm{ml})$ to each well, the plate was incubated for 2 $\mathrm{h}$ to allow the formation of the formazan dye. Absorbance was then measured at $450 \mathrm{~nm}$ using an Absorbance Microplate Reader (SpectraMAX ${ }^{\circledR}$, Molecular Devices, CA, USA). To analyze effects of protective agents, corneal epithelial cells were incubated in a $60-\mathrm{mm}$ dish with $4 \%$ serum containing DMEM/F-12 and grown to $80-90 \%$ confluence before treatment. Cells were treated with $20 \%$ ethanol for $30 \mathrm{~s}$ in the absence or presence of test agents.

Immunoblotting. Corneal epithelial cells were lysed with a buffer containing 1\% NP40, $20 \mathrm{mM}$ Tris-HCL (pH 7.5), $150 \mathrm{mM} \mathrm{NaCl}$, $1 \%$ sodium deoxycholate, $1 \mathrm{mM} \mathrm{Na}{ }_{2}$ EDTA, $1 \mathrm{mM}$ EGTA, $1 \mathrm{mM} \beta$ glycerophosphate, $2.5 \mathrm{mM}$ sodium pyrophosphate, $1 \mathrm{mM} \mathrm{Na} \mathrm{VO}_{4}$, and $1 \mu \mathrm{g} / \mathrm{ml}$ leupeptin. Cell lysates containing proteins were subjected to sodium dodecyl sulfate polyacrylamide gel electrophoresis (SDS-PAGE) and transferred to polyvinylidene difluoride membranes. The membranes were blocked with PBS containing $5 \%$ bovine serum albumin, incubated overnight at $4{ }^{\circ} \mathrm{C}$ with primary antibodies $(1: 1,000)$, followed by incubation with horseradish peroxidase-conjugated secondary antibody for $1 \mathrm{~h}$ at room temperature. The bands were then visualized using enhanced chemiluminescence kits (Amersham Pharmacia, Piscataway, NJ, USA) and a luminescent image analyzer LAS-4000 (Fujifilm, Tokyo, Japan). Band intensities were quantified using ImageJ software (NIH, Bethesda, MD, USA).

Statistical analysis. Data were processed and analyzed using GraphPad Prism 7.04 software (GraphPad Software, San Diego, CA, USA). The mean and standard deviation (SD) were computed for all variables. Normality of data distribution was assessed by using Shapiro-Wilk test. Sphericity was examined by using Mauchley's test. Statistical analysis was performed using RM- 

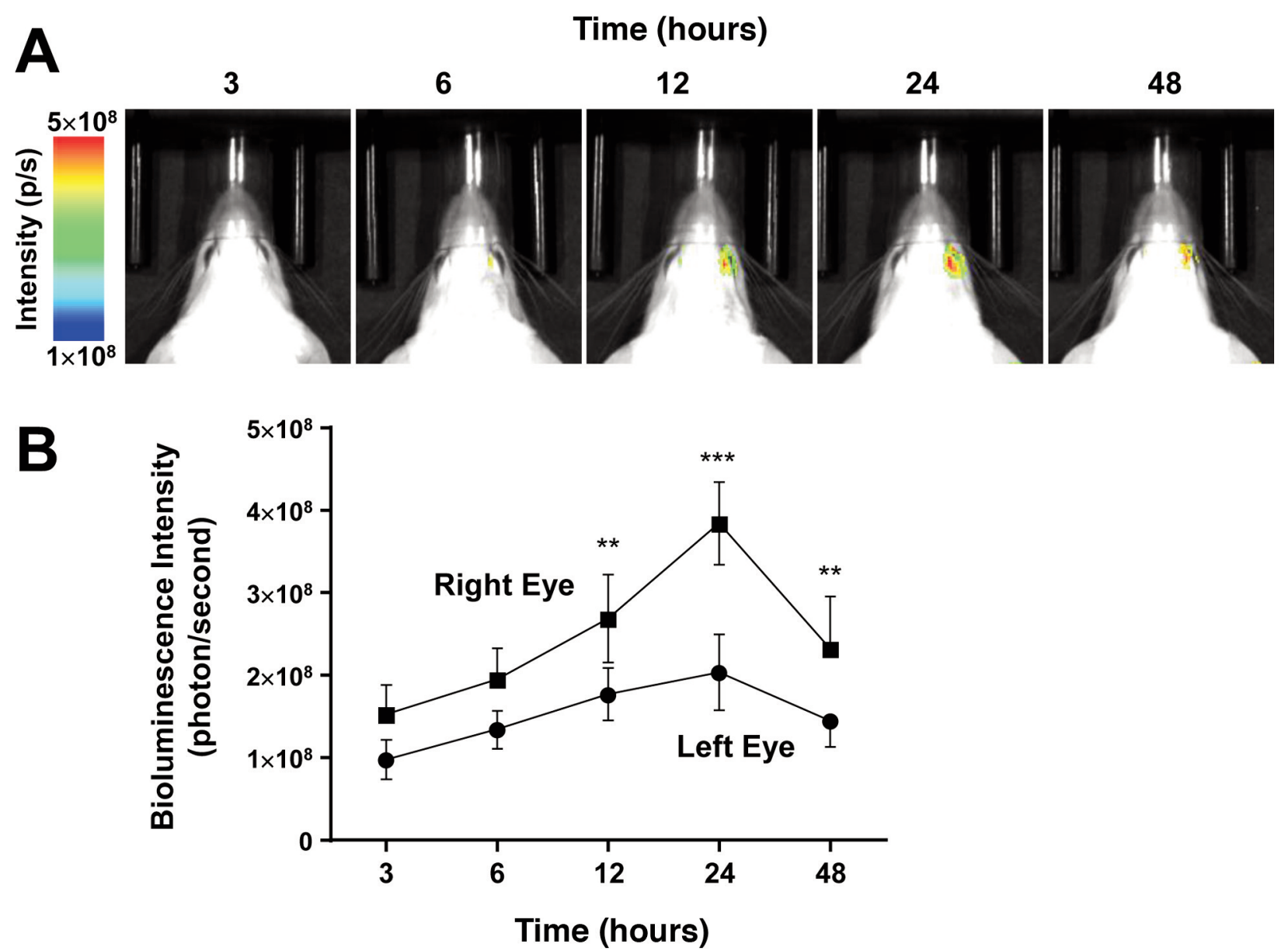

Figure 1. In vivo bioluminescence images of MMP-2/9 activity in response to ethanol. (A) Bioluminescence images of ethanol-treated right eye and saline-treated left eye of mice. (B) ROI analysis of bioluminescence signal was compared between right eye (20\% ethanol) and left eye (saline) $(n=6)$. Data were analyzed by two-way RM ANOVA [interaction $p<0.001 F(4,40)=11.43$; time $p<0.001 F(4,40)=73.37$; treatment $p<0.001 F(1$, $10)=22.28$; subjects $p<0.001 F(10,40)=9.059]$ and post-hoc Sidak's multiple comparisons test (right eye vs. left eye, $12 \mathrm{~h}, p<0.01 ; 24 \mathrm{~h}, p<0.001$; $48 h, p<0.01) . * * p<0.01 ; * * * p<0.001$.

ANOVA, Friedman test, and Kruskal-Wallis test. Post-hoc Dunn's multiple comparisons test was performed to determine statistically significant effects. Statistical significance was set at $p<0.05$.

\section{Results}

In vivo MMP-2/9 bioluminescence image in ethanol-injured cornea. Changes of MMP-2/9-associated intensities were first determined by BLI, and compared between $20 \%$ ethanolinjured and saline-treated control eyes. BLI of MMP-2/9 activity was observed over time (3-48 h) in ethanol-injured right eye (Figure 1A). As shown in Figure 1B, the MMP-2/9associated intensity in BLI at $3 \mathrm{~h}$ was $1.52 \times 10^{8} \pm 3.54 \times 10^{7} \mathrm{p} / \mathrm{s}$. It was elevated gradually, reaching the maximum at $24 \mathrm{~h}$ after injury $\left(3.84 \times 10^{8} \pm 5.03 \times 10^{7} \mathrm{p} / \mathrm{s}\right)$. The intensity showed a slight diminution at $48 \mathrm{~h}\left(2.32 \times 10^{8} \pm 6.34 \times 10^{7} \mathrm{p} / \mathrm{s}\right)$. The right eye had a higher intensity signal in BLI than the saline-treated left eye (Figure 1B). In addition, there were significant differences in the intensity of the signal of MMP-2/9 activity in BLI between the right and left eyes at 12, 24, and $48 \mathrm{~h}$ (Figure 1B).

Effects of agents on MMP-2/9 bioluminescence in ethanolinjured eyes. We next investigated changes in MMP-2/9 signal intensity in BLI after administration of protective eye drops on cornea injured by ethanol. Injured eyes received 10 $\mu \mathrm{l} / \mathrm{mouse}$ of eye drop containing HA $(0.15 \%)$ or high concentration serum $(50 \%)$ and examined at $3 \mathrm{~h}, 6 \mathrm{~h}, 12 \mathrm{~h}$, $24 \mathrm{~h}$, and $48 \mathrm{~h}$ after the injury (Figure 2A). As shown in Figure 2B, MMP-2/9 signal intensity in BLI in response to $20 \%$ ethanol at $24 \mathrm{~h}$ was $4.35 \times 10^{8} \pm 1.09 \times 10^{8} \mathrm{p} / \mathrm{s}$. It was 


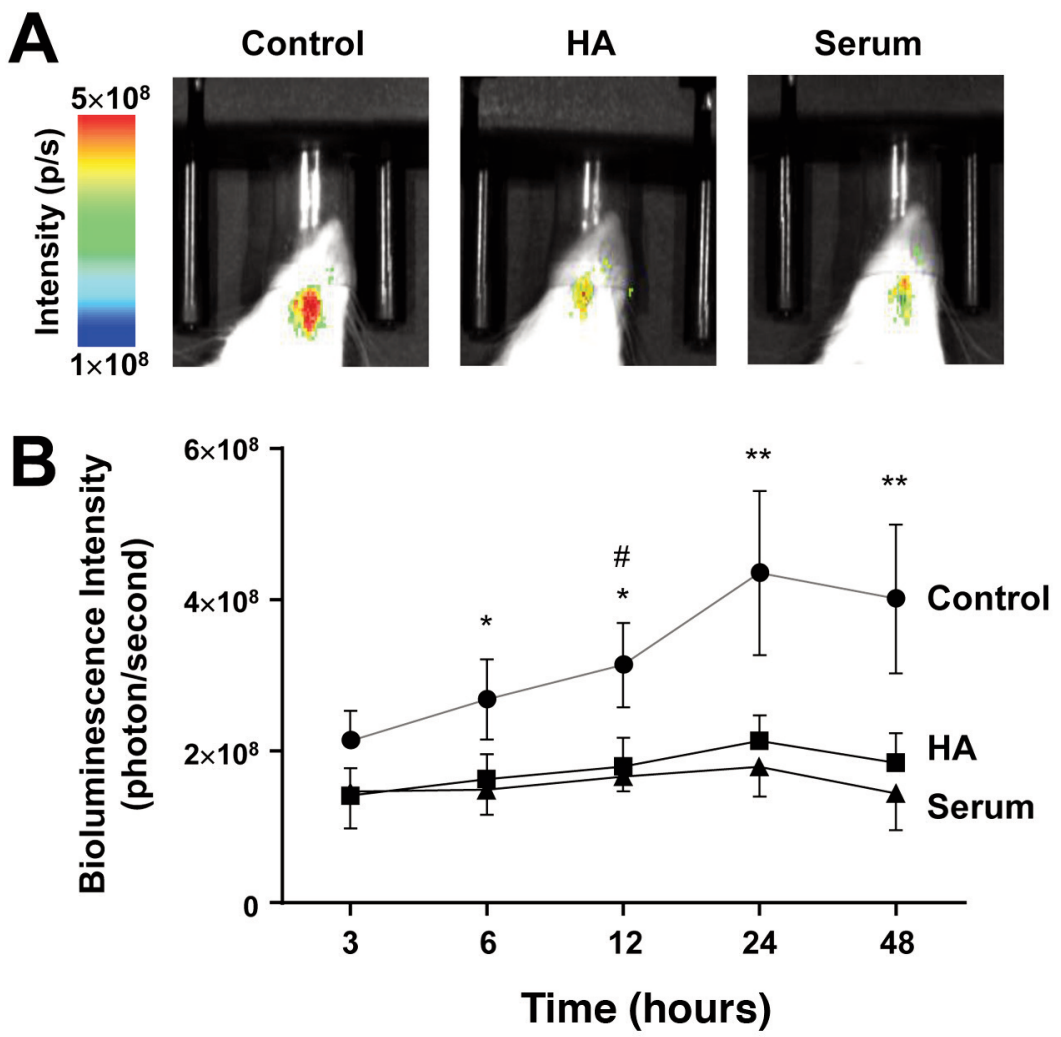

Figure 2. Effects of protective eye drops on bioluminescence images showing MMP-2/9 activity in ethanol-injured right eyes. (A) In vivo bioluminescence images showing MMP-2/9 activity at $24 \mathrm{~h}$ after treatment with hyaluronic acid (HA) and serum. (B) ROI analysis of bioluminescence signal was compared between each group for right eyes (control, $n=5 ; H A, n=5$; serum, $n=5$ ). Data were analyzed with Friedman test ( $p<0.001)$ and then post-hoc Dunn's multiple comparisons test after Kruskal-Wallis test (*control vs. serum at 6 h, $p<0.05$; **control vs. serum at 12 h, $p<0.01$; ${ }^{*}$ control vs. HA at 12 h, $p<0.05$; ** control vs. serum at $24 \mathrm{~h}, p<0.01$; " control vs. HA at $24 h, p<0.05 ; * *$ control vs. serum at $48 h, p<0.01)$.

inhibited by HA and serum to $2.12 \times 10^{8} \pm 3.38 \times 10^{7} \mathrm{p} / \mathrm{s}$ and $1.8 \times 10^{8} \pm 3.94 \times 10^{7} \mathrm{p} / \mathrm{s}$, respectively. Their BLI intensities at $6 \mathrm{~h}, 12 \mathrm{~h}, 24 \mathrm{~h}$, and $48 \mathrm{~h}$ in the serum treated-group and those in the HA-treated group at $12 \mathrm{~h}$ and $24 \mathrm{~h}$ were significantly different from those in ethanol-injured control group (Figure 2B).

Effects of ethanol and agents on MMP activation in corneal epithelial cells. To validate the results obtained by BLI analysis using MMP-2/9 activity probe, the activities of MMP-2 and MMP-9 were examined using primary corneal epithelial cells treated with HA and high concentration serum. We first determined the effects of ethanol and protective eye drops on cell viability. Treatment with ethanol $(20-100 \%)$ for $30 \mathrm{~s}$ inhibited the viability of corneal epithelial cells in a concentration-dependent manner (Figure $3 \mathrm{~A})$. HA (0.01-0.3\%) significantly reversed the decrease in cell viability in response to treatment with ethanol $20 \%$ for 30 s (Figure 3B). Similar to HA, serum (20-50\%) also reversed the decrease in viability of cells treated with ethanol, which was significant at concentrations of $40 \%$ and $50 \%$ (Figure 3C).

As shown in Figure 4, treatment of corneal epithelial cells with 20\% ethanol increased cleavage and activation of MMP-2 as well as activation of MMP-9. However, treatment with $20 \%$ ethanol did not change the expression levels of MMP-2 or MMP-9 (Figure 4A and D). Elevated activities of MMP-2 and MMP-9 at $0.5 \mathrm{~h}, 1 \mathrm{~h}$, and $3 \mathrm{~h}$ after treatment with $20 \%$ ethanol were attenuated upon treatment with HA $(0.1 \%)$ (Figure 4A-C) and serum (50\%) (Figure 4D-F). However, treatment of cells with ethanol, HA, or serum did not affect the expression of $\beta$-actin that was used as a housekeeping protein (Figure 4A and D).

\section{Discussion}

In the present study, we showed using BLI that ethanol treatment elevated MMP activity in the cornea of mice injected with MMP-2/9 probe. In vivo BLI is a powerful technique that plays a crucial role in diagnosis and initial 

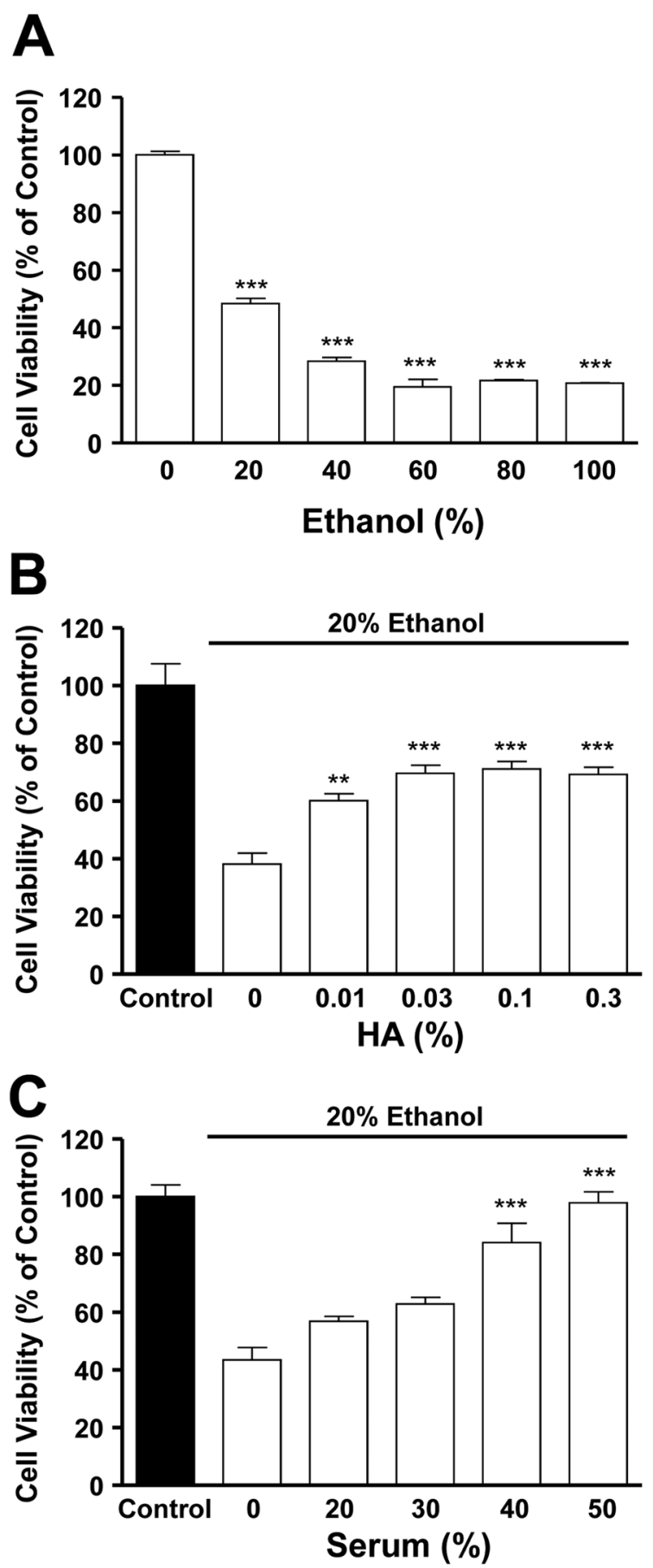

Figure 3. Effects of ethanol and protective eye drops on the viability of corneal epithelial cells. (A) Effects of ethanol on viability of corneal epithelial cells. Corneal epithelial cells were treated with ethanol (20100\%) for $30 \mathrm{s.}$ (B and C) Effects of protective agents on the viability of corneal epithelial cells injured with ethanol. Hyaluronic acid (HA; $0.01-0.3 \%)(B)$ and high concentration serum (20-50\%) (C) were used to treat corneal epithelial cells injured with $20 \%$ ethanol for $30 \mathrm{~s}$. The levels of viability were determined using an XTT assay as described in the Methods section. Cell viability of the untreated-treated group (control) was expressed as $100 \%(n=8)$. *** $p<0.001 \mathrm{vs}$. control (A). ${ }^{* *} p<0.01, *^{* *} p<0.001 \mathrm{vs.}$ ethanol alone, respectively ( $B$ and $\left.C\right)$. management of a variety of disease processes at the molecular level (22). The luminescence probe (NpFlamma ${ }^{\circledR}$ MMP-2/9 probe, BioActs) used in this study comprised a Flamma ${ }^{\circledR}$ Fluor 675 dye that was linked to a quencher through MMP2,9 cleavable peptide. It can be used for monitoring MMPrelated diseases and evaluating the potential therapeutic efficacy of drugs targeting these diseases (23). However, the use of BLI to investigate ocular surface injury for MMP-2 and MMP-9 has not been reported yet. Furthermore, it is known that mRNA expression levels of MMP isoforms are upregulated in corneal epithelial cells at $18 \mathrm{~h}$ after corneal abrasion injury (24). In the present study, MMP-2/9 signal intensity in BLI was elevated gradually up to $24 \mathrm{~h}$ after ethanol-induced injury. The intensity of the signal was slightly reduced at $48 \mathrm{~h}$. Moreover, protective effects of eye drops with $\mathrm{HA}$ and high serum were obtained from $6 \mathrm{~h}$ to $48 \mathrm{~h}$. These results imply that ethanol-induced injury results in long-term activation of MMP-2 and MMP-9 and that eye drops with HA and serum may have long-term effects on MMP-2/9 activity during corneal wound healing. From these results, it can be assumed that changes of MMP-2/9 activity based on its intensity in BLI are tightly associated with altered MMP-2 and MMP-9 activation during the development and repair of corneal injury in response to treatments with ethanol and protective eye drops.

In the present study, ethanol decreased the viability of corneal cells in a dose-dependent manner. Moreover, this study confirmed that the activities of MMP-2 and MMP-9 were elevated in corneal epithelial cells treated with $20 \%$ ethanol. A similar pattern was found by ocular BLI in response to ethanol treatment. These results imply that a high concentration of ethanol can induce corneal cell injury via a pathway involving MMPs, thus influencing corneal cell viability. Previously, it has been shown that ethanol and alkali solution application can increase MMP-9 expression in corneal epithelial cells $(10,25)$. It has been demonstrated that both MMP-2 and MMP-9 may disrupt corneal epithelial integrity by proteolytic cleavage of occludin, a component of intracellular tight junction (26-28). The activities of MMP-2 and MMP-9 can be inhibited by GM6001, an MMP inhibitor, in corneal cells (27). These results confirmed that activation of MMPs, especially MMP-2 and MMP-9, may play important roles in the development and repair of corneal injury induced by ethanol treatment.

Moreover, in the present study, HA eye drop significantly decreased MMP-2/9 activity based on BLI signal intensity that was elevated by ethanol treatment. HA also inhibited the activity of MMP-2 and MMP-9 in corneal epithelial cells. HA has high binding affinity for water. Thus, it can act as a reservoir to slowly release water molecules (29). HA can accelerate epithelial cell migration and protect the ocular surface by increasing the expression of MMP-2 and MMP-9 (30). Thus, HA eye drops are commonly used to treat dry eye 

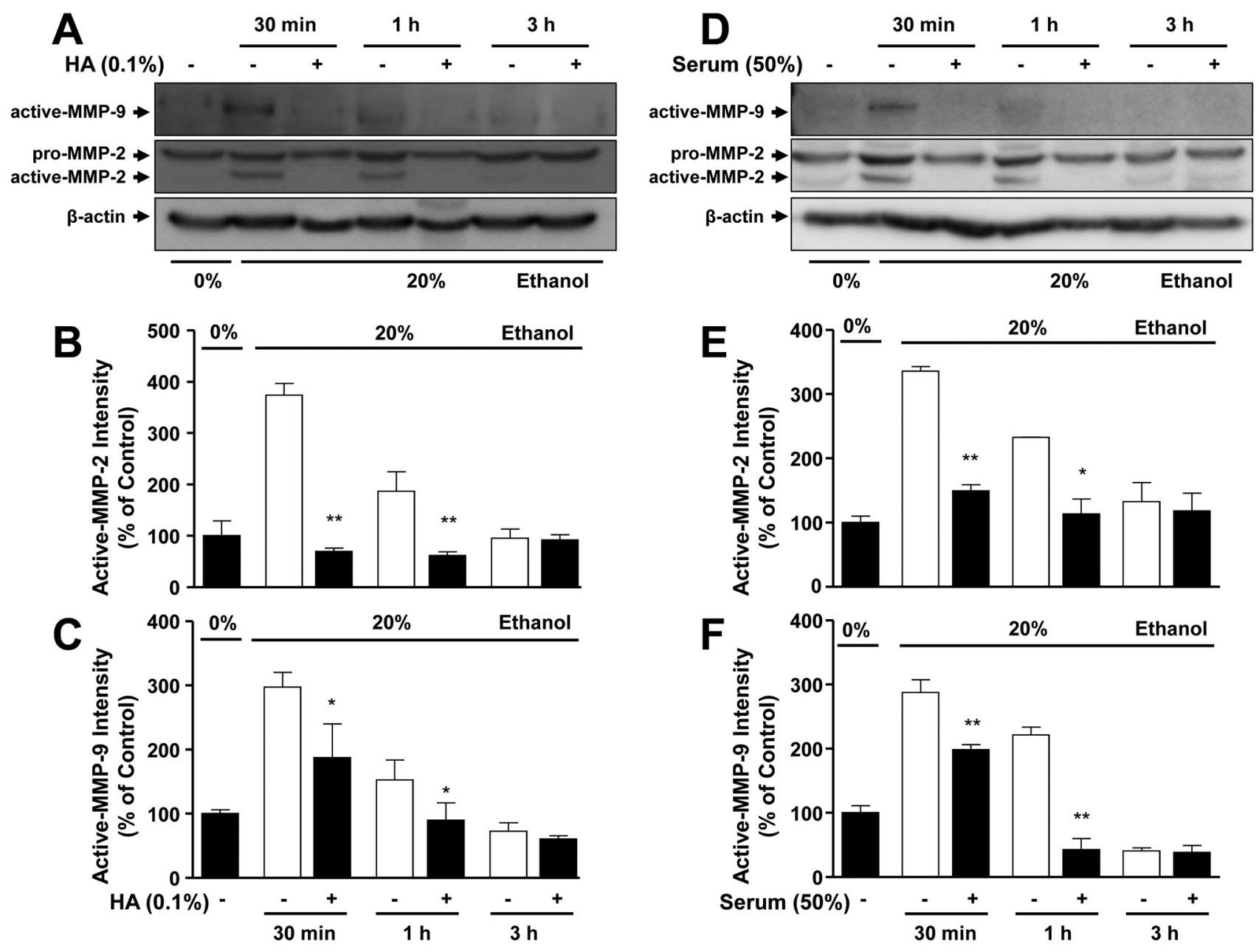

Figure 4. Effects of protective eye drops on the activation of MMP-2 and MMP-9 in corneal epithelial cells. (A and D) Corneal epithelial cells were treated with $20 \%$ ethanol for $30 \mathrm{~s}$ and then incubated in the absence or presence of hyaluronic acid (HA; $0.1 \%)(A)$ and high concentration serum $(50 \%)$ for the indicated times $(D)$. Cell lysates were immunoblotted with anti-MMP-2 and anti-MMP-9. $\beta$-actin was used as a housekeeping protein for each test protein. (B and C) Quantification of the data obtained from panel A. (E and F) Quantification of the data obtained from panel D. Enzyme activation was determined by the expression of cleaved MMP-2 and active MMP-9 on blots. Expression of each protein in untreated group was expressed as $100 \%(n=4) .{ }^{*} p<0.05, * * p<0.01 \mathrm{vs}$. ethanol alone at indicated time point, respectively.

disease. From these results, it can be hypothesized that MMP activity plays a central role in the process of development of alcohol-induced corneal injury and HA facilitates healing. Furthermore, accumulated results have shown that autologous serum is beneficial in promoting corneal epithelial migration and providing accelerated epithelial healing $(31,32)$. Serum may include several proteins that can act as antioxidant and free radical scavengers. It is known that corneal cell injury is accompanied by imbalanced antioxidant protection systems (33). Furthermore, it has been shown that serum can diminish the expression and activity of MMP in corneal cells (34). A similar result was obtained using corneal epithelial cells in the present study. The present study also revealed that eye drop with a high concentration of serum could potently diminish MMP-2/9 activity. Although the mechanisms through which serum and HA promote corneal wound healing are not fully understood yet, these results imply that serum and HA can act as inhibitors of MMP activity. These results suggest that HA and serum can promote corneal wound healing by inhibiting the activities of MMP-2 and MMP-9. Thus, regulating these enzymes would be a new strategy to develop drugs for topical eye application with major clinical effects.

In conclusion, the present study showed using BLI that treatment with $20 \%$ ethanol increased MMP-2/9 activity. The application of protective eye drops (serum and HA) 
significantly inhibited MMP-2/9 activity as assayed by BLI after ethanol-induced injury. These results indicate that MMP-2 and MMP-9 activities may be tightly involved in the development of corneal damage and healing by eye drops containing protective agents. Results of this study also suggest that BLI is a useful tool for determining in vivo the activities of MMPs and monitoring the efficacy and mechanism of drug action in corneal epithelial disorders.

\section{Conflicts of Interest}

The Authors have no conflicts of interest to declare regarding this study.

\section{Authors' Contributions}

S.B.P., S.H.J. B.K., H.J.S., and K.-J.W. conceived and designed the work. S.B.P., S.H.J., H.J., S.J.K., and K.-J.L. carried out experiments and data acquisition. B.K., H.J.S., and K.-J.W. wrote the manuscript. S.B.P. and Y.R. verified the analytical methods. All Authors discussed the results and contributed to the final manuscript.

\section{Acknowledgements}

This research was supported by a grant of the Korea Health Technology R\&D Project through the Korea Health Industry Development Institute (KHIDI) funded by the Ministry of Health and Welfare, Republic of Korea (HI15C1540).

\section{References}

1 Dua HS, Ting DSJ, Al Saadi A and Said DG: Chemical eye injury: pathophysiology, assessment and management. Eye (Lond) 34(11): 2001-2019, 2020. PMID: 32572184. DOI: 10.1038/s41433-020-1026-6

2 Hwang HB, Oh TH and Kim HS: Effect of ethanol-treated midperipheral epithelium on corneal wound healing in rabbits. BMC Ophthalmol 13: 27, 2013. PMID: 23822645. DOI: 10.1186/14712415-13-27

3 Oh JY, Yu JM and Ko JH: Analysis of ethanol effects on corneal epithelium. Invest Ophthalmol Vis Sci 54(6): 3852-3856, 2013. PMID: 23674759. DOI: 10.1167/iovs.13-11717

4 Chen CC, Chang JH, Lee JB, Javier J and Azar DT: Human corneal epithelial cell viability and morphology after dilute alcohol exposure. Invest Ophthalmol Vis Sci 43(8): 2593-2602, 2002. PMID: 12147590

5 Sivak JM and Fini ME: MMPs in the eye: emerging roles for matrix metalloproteinases in ocular physiology. Prog Retin Eye Res 21(1): 1-14, 2002. PMID: 11906808. DOI: 10.1016/s13509462(01)00015-5

6 Chang JH, Huang YH, Cunningham CM, Han KY, Chang M, Seiki M, Zhou Z and Azar DT: Matrix metalloproteinase 14 modulates signal transduction and angiogenesis in the cornea. Surv Ophthalmol 61(4): 478-497, 2016. PMID: 26647161. DOI: 10.1016/j.survophthal.2015.11.006

7 Lyu J and Joo CK: Expression of Wnt and MMP in epithelial cells during corneal wound healing. Cornea 25(10 Suppl 1): S24-S28,
2006. PMID: 17001188. DOI: 10.1097/01.ico.0000247209.012 $62.4 \mathrm{e}$

8 Wu ZQ, Zhang ZL, Nie SW, Yuan J and Yang YN: Activity of matrix metalloproteinases 2 and 9 in cultured rabbit corneal epithelium cells stimulated by tumor necrosis factor alpha. Genet Mol Res 14(2): 6360-6368, 2015. PMID: 26125840. DOI: 10.4238/2015.June.11.11

9 Barros LF, Barros PS, Röpke CD, Silva VV, Sawada TC, Barros $\mathrm{SB}$ and Belfort R Jr: Dose-dependent in vitro inhibition of rabbit corneal matrix metalloproteinases by an extract of Pothomorphe umbellata after alkali injury. Braz J Med Biol Res 40(8): 1129-1132, 2007. PMID: 17665050 . DOI: 10.1590/s0100-879x2006005000120

10 Song IK and Joo CK: Morphological and functional changes in the rat cornea with an ethanol-mediated epithelial flap. Invest Ophthalmol Vis Sci 45(2): 423-428, 2004. PMID: 14744881. DOI: 10.1167/iovs.03-0947

11 Sharma C, Velpandian T, Baskar Singh S, Ranjan Biswas N, Bihari Vajpayee R and Ghose S: Effect of fluoroquinolones on the expression of matrix metalloproteinase in debrided cornea of rats. Toxicol Mech Methods 21(1): 6-12, 2011. PMID: 21058936. DOI: 10.3109/15376516.2010.529183

12 Sakuma M, Miyachi S and Sakamoto T: The effect of sodium hyaluronate on the expression of gelatinases in rabbit corneal epithelial wound healing. Jpn J Ophthalmol 44(5): 475-481, 2000. PMID: 11033124. DOI: 10.1016/s0021-5155(00)00208-2

13 Taheri F and Bazan HE: Platelet-activating factor overturns the transcriptional repressor disposition of $\mathrm{Sp} 1$ in the expression of MMP-9 in human corneal epithelial cells. Invest Ophthalmol Vis Sci 48(5): 1931-1941, 2007. PMID: 17460244. DOI: 10.1167/ iovs.06-1008

14 Mori M, De Lorenzo E, Torre E, Fragai M, Nativi C, Luchinat $\mathrm{C}$ and Arcangeli A: A highly soluble matrix metalloproteinase-9 inhibitor for potential treatment of dry eye syndrome. Basic Clin Pharmacol Toxicol 111(5): 289-295, 2012. PMID: 22520332. DOI: $10.1111 / \mathrm{j} .1742-7843.2012 .00896 . x$

15 Mezzanotte L, van't Root M, Karatas H, Goun EA and Löwik CWGM: In vivo molecular bioluminescence imaging: New tools and applications. Trends Biotechnol 35(7): 640-652, 2017. PMID: 28501458. DOI: 10.1016/j.tibtech.2017.03.012

16 Massey S, Johnston K, Mott TM, Judy BM, Kvitko BH, Schweizer HP, Estes DM and Torres AG: In vivo bioluminescence imaging of Burkholderia mallei respiratory infection and treatment in the mouse model. Front Microbiol 2: 174, 2011. PMID: 21904535. DOI: 10.3389/fmicb.2011.00174

17 Ji X, Cheng L, Wei F, Li H, Wang M, Tian Y, Chen X, Wang Y, Wolf F, Li C and Huang Q: Noninvasive visualization of retinoblastoma growth and metastasis via bioluminescence imaging. Invest Ophthalmol Vis Sci 50(12): 5544-5551, 2009. PMID: 19608529. DOI: 10.1167/iovs.08-3258

18 Gutowski MB, Wilson L, Van Gelder RN and Pepple KL: In vivo bioluminescence imaging for longitudinal monitoring of inflammation in animal models of uveitis. Invest Ophthalmol Vis Sci 58(3): 1521-1528, 2017. PMID: 28278321. DOI: 10.1167/iovs.16-20824

19 Corson TW, Samuels BC, Wenzel AA, Geary AJ, Riley AA, McCarthy BP, Hanenberg H, Bailey BJ, Rogers PI, Pollok KE, Rajashekhar G and Territo PR: Multimodality imaging methods for assessing retinoblastoma orthotopic xenograft growth and development. PLoS One 9(6): e99036, 2014. PMID: 24901248. DOI: 10.1371/journal.pone.0099036 
20 Ezra-Elia R, Obolensky A, Ejzenberg A, Ross M, Mintz D, Banin $\mathrm{E}$ and Ofri R: Can an in vivo imaging system be used to determine localization and biodistribution of AAV5-mediated gene expression following subretinal and intravitreal delivery in mice? Exp Eye Res 176: 227-234, 2018. PMID: 30171858. DOI: 10.1016/j.exer.2018.08.021

21 Head T, Dau P, Duffort S, Daftarian P, Joshi PM, VazquezPadron R, Deo SK and Daunert S: An enhanced bioluminescence-based Annexin V probe for apoptosis detection in vitro and in vivo. Cell Death Dis 8(5): e2826, 2017. PMID: 28542141. DOI: $10.1038 /$ cddis.2017.141

22 Panth KM, van den Beucken T, Biemans R, Lieuwes NG, Weber $\mathrm{M}$, Losen M, Yaromina A, Dubois LJ and Lambin P: In vivo optical imaging of MMP2 immuno protein antibody: tumor uptake is associated with MMP2 activity. Sci Rep 6: 22198, 2016. PMID: 26923459. DOI: 10.1038/srep22198

23 Lee S, Park K, Lee SY, Ryu JH, Park JW, Ahn HJ, Kwon IC, Youn IC, Kim K and Choi K: Dark quenched matrix metalloproteinase fluorogenic probe for imaging osteoarthritis development in vivo. Bioconjug Chem 19(9): 1743-1747, 2008. PMID: 18729392. DOI: $10.1021 / \mathrm{bc} 800264 \mathrm{z}$

24 Gordon GM, Austin JS, Sklar AL, Feuer WJ, LaGier AJ and Fini ME: Comprehensive gene expression profiling and functional analysis of matrix metalloproteinases and TIMPs, and identification of ADAM-10 gene expression, in a corneal model of epithelial resurfacing. J Cell Physiol 226(6): 1461-1470, 2011. PMID: 20625997. DOI: $10.1002 /$ jcp.22306

25 Gao M, Sang W, Liu F, Yu H, Zhou R, Belin MW, Zloty P and Chen Y: High MMP-9 expression may contribute to retroprosthetic membrane formation after KPro implantation in rabbit corneal alkali burn model. J Ophthalmol 2016: 1094279 , 2016. PMID: 26949542. DOI: 10.1155/2016/1094279

26 Huet E, Vallée B, Delbé J, Mourah S, Prulière-Escabasse V, Tremouilleres M, Kadomatsu K, Doan S, Baudouin C, Menashi $\mathrm{S}$ and Gabison EE: EMMPRIN modulates epithelial barrier function through a MMP-mediated occludin cleavage: Implications in dry eye disease. Am J Pathol 179(3): 1278-1286, 2011. PMID: 21777561. DOI: 10.1016/j.ajpath.2011.05.036
27 Rajashekhar G, Shivanna M, Kompella UB, Wang Y and Srinivas SP: Role of MMP-9 in the breakdown of barrier integrity of the corneal endothelium in response to TNF- $\alpha$. Exp Eye Res 122: 7785, 2014. PMID: 24667088. DOI: 10.1016/j.exer.2014.03.004

28 Wiechmann AF, Ceresa BP and Howard EW: Diurnal variation of tight junction integrity associates inversely with matrix metalloproteinase expression in Xenopus laevis corneal epithelium: Implications for circadian regulation of homeostatic surface cell desquamation. PLoS One 9(11): e113810, 2014. PMID: 25412440. DOI: 10.1371/journal.pone.0113810

29 Sudha PN and Rose MH: Beneficial effects of hyaluronic acid. Adv Food Nutr Res 72: 137-176, 2014. PMID: 25081082. DOI: 10.1016/B978-0-12-800269-8.00009-9

30 Robert L, Robert AM and Renard G: Biological effects of hyaluronan in connective tissues, eye, skin, venous wall. Role in aging. Pathol Biol (Paris) 58(3): 187-198, 2010. PMID: 19932571. DOI: 10.1016/j.patbio.2009.09.010

31 Schulze SD, Sekundo W and Kroll P: Autologous serum for the treatment of corneal epithelial abrasions in diabetic patients undergoing vitrectomy. Am J Ophthalmol 142(2): 207-211, 2006. PMID: 16876497. DOI: 10.1016/j.ajo.2006.04.017

32 Wirostko B, Rafii M, Sullivan DA, Morelli J and Ding J: Novel therapy to treat corneal epithelial defects: A hypothesis with growth hormone. Ocul Surf 13(3): 204-212.e1, 2015. PMID: 26045234. DOI: $10.1016 /$ j.jtos.2014.12.005

33 Cejka C and Cejkova J: Oxidative stress to the cornea, changes in corneal optical properties, and advances in treatment of corneal oxidative injuries. Oxid Med Cell Longev 2015: 591530, 2015. PMID: 25861412. DOI: 10.1155/2015/591530

34 Watson SL, Secker GA and Daniels JT: The effect of therapeutic human serum drops on corneal stromal wound-healing activity. Curr Eye Res 33(8): 641-652, 2008. PMID: 18696339. DOI: $10.1080 / 02713680802254790$

Received December 11, 2020

Revised February 16, 2021

Accepted February 17, 2021 